University of Nebraska - Lincoln

DigitalCommons@University of Nebraska - Lincoln

\title{
Size-Dependent Feeding and Reproduction by Boll Weevil (Coleoptera: Curculionidae)
}

\author{
S. M. Greenberg \\ Kika de la Garza Subtropical Agricultural Research Center, sgreenberg@weslaco.ars.usda.gov \\ D. W. Spurgeon \\ USDA-ARS
}

Thomas W. Sappington

USDA-ARS, tsapping@iastate.edu

M. Sétamou

USDA-ARS

Follow this and additional works at: https://digitalcommons.unl.edu/usdaarsfacpub

Part of the Agricultural Science Commons

Greenberg, S. M.; Spurgeon, D. W.; Sappington, Thomas W.; and Sétamou, M., "Size-Dependent Feeding and Reproduction by Boll Weevil (Coleoptera: Curculionidae)" (2005). Publications from USDA-ARS / UNL Faculty. 730.

https://digitalcommons.unl.edu/usdaarsfacpub/730

This Article is brought to you for free and open access by the U.S. Department of Agriculture: Agricultural Research Service, Lincoln, Nebraska at DigitalCommons@University of Nebraska - Lincoln. It has been accepted for inclusion in Publications from USDA-ARS / UNL Faculty by an authorized administrator of DigitalCommons@University of Nebraska - Lincoln. 


\title{
Size-Dependent Feeding and Reproduction by Boll Weevil (Coleoptera: Curculionidae)
}

\author{
S. M. GREENBERG,${ }^{1}$ D. W. SPURGEON ${ }^{2}$ T. W. SAPPINGTON ${ }^{3}$ AND M. SÉTAMOU ${ }^{4}$
}

Areawide Pest Management Research Unit, USDA-ARS, 2413 East Highway 83, Weslaco, TX 78596

\begin{abstract}
J. Econ. Entomol. 98(3): 749-756 (2005)
ABSTRACT The considerable variation in adult size of the boll weevil, Anthonomus grandis grandis Boheman, has been well documented, but the influences of adult size on reproductive rate are not known. We examined the relationship between the size of boll weevils and their feeding and oviposition. Weevils weighed to the nearest milligram were grouped into five categories based on pupal weight: $\leq 5,6-10,11-15,16-20$, and $>20 \mathrm{mg}$. Numbers of lifetime punctures produced in flower buds (squares) of cotton, Gossypium hirsutum L., by both sexes of adults tended to increase with pupal weight. Boll weevil females with pupal weights $>10 \mathrm{mg}$ produced progeny with significantly higher survival to adulthood and also produced a higher percentage of female progeny than those with pupal weights $\leq 10 \mathrm{mg}$. The population growth indices for females having pupal weights $>10 \mathrm{mg}$ averaged 1.8-fold higher than those of females weighing $\leq 10 \mathrm{mg}$. Survivorship of adults of both sexes also tended to increase with pupal weight. The percentage of females laying eggs on any given day averaged 2.1 times higher when their pupal weights were $>10 \mathrm{mg}$ than when their pupal weights were $\leq 10 \mathrm{mg}$. Although small size negatively affected female reproductive potential, even extremely small females produced some viable offspring. However, the penalties of small adult size, in terms of longevity and reproductive potential, suggest that cultural practices that result in the production of small adults may be used to impact weevil populations.
\end{abstract}

KEY WORDS Anthonomus grandis grandis, boll weevil, reproductive indices, cotton

THE CONSIDERABLE VARIATION IN adult size of the boll weevil, Anthonomus grandis grandis Boheman, is well documented (Mally 1901, Newell et al. 1926, Little and Martin 1942). Most studies have considered the source of this variation to be dietary, with limited food quality or availability resulting in smaller weevils. In particular, the production of small adult weevils has been associated with the infestation of undersized flower buds (squares) of cotton, Gossypium hirsutum L.) (Mally 1901, Smith 1921, Bailey et al. 1967), although there is an indication that this relationship may vary among species of cotton (Black and Leigh 1963). Other conditions also may impact the diet to produce small adults. Curry et al. (1982) constructed a model of boll weevil mortality based on the desiccation rates of abscised squares. The premise of this model was that rapid square desiccation would result in starvation of the developing boll weevil larva. During an examina-

\footnotetext{
This article reports the results of research only. Mention of a proprietary product does not constitute an endorsement or a recommendation by the USDA for its use.

${ }^{1}$ Corresponding author, e-mail: sgreenberg@weslaco.ars.usda.gov.

${ }^{2}$ Areawide Pest Management Research Unit, USDA-ARS, College Station, TX 77845.

${ }^{3}$ Current address: Corn Insects and Crop Genetics Research Unit, USDA-ARS, Ames, IA 50011.

${ }^{4}$ Subtropical Agricultural Research Center, USDA-ARS, Weslaco, TX 78596.
}

tion of this premise, Reardon and Spurgeon (2002) removed larvae from food at different times to determine the critical weight beyond which development to adulthood would occur without further feeding. Although their conclusions questioned the prominence of the role of square desiccation in the production of mortality, the results emphasized that variation in access to a food supply among larvae could result in a wide (1.61-21.49 $\mathrm{mg}$ ) range of adult sizes. Based on observations of infested square collections (D.W.S., unpublished data), the production of small adult weevils is likely to occur most often early in the growing season when available squares are small, and near the time of crop maturity, when the numbers of squares are limited, weevil populations are high, and most squares are heavily fed upon.

Substantial effort has been devoted to understanding the factors that contribute to natural mortality in the boll weevil (Smith 1936; Sturm and Sterling 1986, 1990; Sturm et al. 1990), and the manipulation of these factors through cultural practices has been investigated in some production systems (Slosser 1981, Slosser et al. 1986). However, the emphasis of most of these efforts was on increasing mortality in the boll weevil population without regard to the potential impacts of an altered size distribution of adults. Because no previous study has examined the population level 
consequences of variable adult size, our objective was to examine the respective relationships between pupal weight and subsequent feeding and reproductive activities of boll weevils.

\section{Materials and Methods}

Experimental Insects and Reproductive Conditioning. Adult boll weevils were obtained from infested squares collected from the ground in cotton fields in the Lower Rio Grande Valley of Texas in the 2001 and 2002 growing seasons. Squares were carefully dissected to confirm infestation, and those with live third instars were closed and held within screened cages in an environmental chamber at $28 \pm 1^{\circ} \mathrm{C}, 65 \% \mathrm{RH}$, and a photoperiod of 14:10 (L:D) h. Temperature and humidity were monitored by a Fisher-brand traceable relative humidity meter with temperature readout (catalog no. 11-661-12; Control Company, Friendswood, TX). When $\approx 60 \%$ of boll weevil larvae had pupated, the pupae were harvested, weighed to the nearest milligram, and placed individually in petri dishes ( 35 by $10 \mathrm{~mm}$ ) containing a thin layer of moist vermiculite.

Pupal weight categories were $\leq 5,6-10,11-15,16$ 20 , and $>20 \mathrm{mg}$. Because the sizes of pupae available in naturally infested squares varied seasonally, weevils assigned to different weight classes were generally obtained from different square collections. Adult weevils corresponding to pupal weight classes of $\leq 5$ and 6-10 mg were obtained from square collections between 15 April and 31 May, and in September. Adults corresponding to other pupal weight classes were obtained from square collections in June through August.

Pupae were examined daily until adult eclosion. Adults were sexed as described by Sappington and Spurgeon (2000), and males were marked with a red paint pen on the right elytron. Newly eclosed weevils from the same pupal weight categories were held in male-female pairs in 90 by 15 -mm plastic petri dishes in an environmental chamber maintained at $28 \pm 1^{\circ} \mathrm{C}$, $65 \% \mathrm{RH}$, and a photoperiod of 14:10 (L:D) h. Daily for $5 \mathrm{~d}$, each pair was provided with five undamaged cotton squares (7-9 mm in diameter at the widest part of the flower bud and with intact bracteoles) and a cotton wick saturated with water. We assumed all females were mated by the end of this 5 -d conditioning period.

Experimental Procedure. Observations were made on groups of weevils distinguished by their pupal weights. Because weevils of different weight classes generally became available at different times, individual male and female weevils were incorporated into the experiment until sample sizes of $30,36,40,41$, and 25 weevils of each sex were attained for respective weight classes of $\leq 5,6-10,11-15,16-20$, and $>20 \mathrm{mg}$. After the conditioning period to allow mating and preoviposition development, each weevil was held individually in a 150 by 20 -mm plastic petri dish with a 40-mm diameter nylon screen window on top. Each weevil was provided five uninfested greenhousegrown squares (7-9 mm diameter at the widest part of the flower bud and with bracteoles intact) daily until weevil death. Squares were removed and examined each day for feeding and oviposition punctures (females) or only for feeding punctures (males). Unsealed punctures were considered as feeding punctures. Oviposition punctures were distinguished by a frass plug and/or a waxy substance either closing the puncture or present on the periphery of the puncture. Everett and Ray (1962) reported a correlation between the numbers of sealed punctures and the numbers of eggs that weevils deposited. Therefore, we used the numbers of sealed punctures as a relative estimate of egg numbers.

In addition to monitoring feeding and oviposition, the percentage of eggs that ultimately produced an adult, and the sex ratio of adult progeny, were estimated from cohorts of squares.

Distinct cohorts of randomly selected ovipositionpunctured squares were periodically obtained from each pupal weight category. To avoid underestimating the production of adults because of larval cannibalism, only squares containing a single oviposition puncture were selected. The number of oviposition-punctured squares in each cohort varied based on their availability. Totals of $12,24,21,19$, and 14 cohorts containing $70,133,111,159$, and 117 oviposition-punctured squares, respectively, were obtained from pupal weight classes of $\leq 5,6-10,11-15,16-20$, and $>20 \mathrm{mg}$. Each cohort was held in a 150 by $20-\mathrm{mm}$ plastic petri dish vented as described previously. Square cohorts were maintained under the same environmental conditions as the adults. Plates were observed daily for newly emerged adults beginning on day 12 and until day 20 after oviposition. After day 20, squares were opened to determine whether additional live weevils remained.

Finally, individual oviposition-punctured squares were periodically collected from each pupal weight class (until a total of 10 adults were obtained per weight class) for estimation of weevil developmental time. These squares were maintained under the same environmental conditions as the square cohorts, except that they were held singly so the developmental time from egg to adult emergence could be determined.

Statistical Analyses. Because pupae, both within and among weight classes, were collected at various times and no single collection yielded pupae of all weight classes, collections within a weight class were pooled for analysis. Before feeding and oviposition data were pooled, they were examined for homogeneity of variance within each pupal weight class. Based on Fisher tests (Sokal and Rohlf 1995), data for feeding punctures of males $\left(F_{\text {calculated }}<1.61 ; \mathrm{df}=9,19 ; P>0.05\right)$, and total punctures (feeding plus oviposition punctures $)$ of females $\left(F_{\text {calculated }}<1.53\right.$; df $=9,19 ; P>$ $0.05)$ exhibited homogeneous variances.

Total lifetime punctures were examined by twoway analysis of variance (ANOVA) by using PROC GLM of SAS (SAS Institute 1999), with weevil sex, pupal weight class, and their interaction as model effects. Data for lifetime oviposition, female adult lon- 


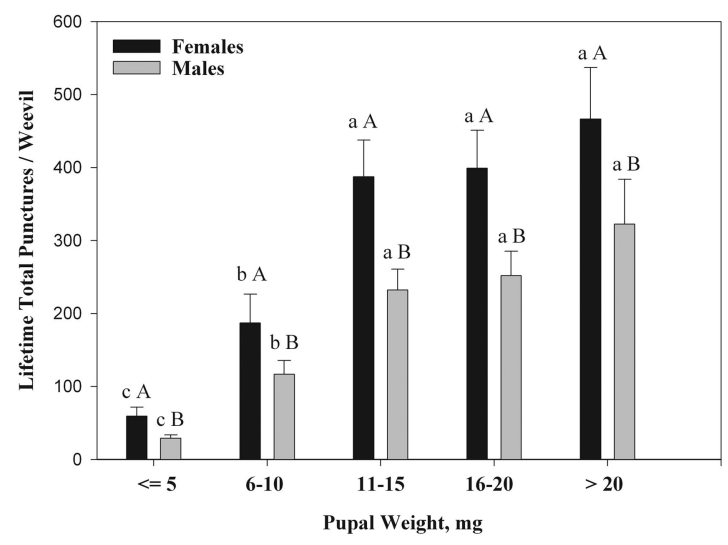

Fig. 1. Mean \pm SE lifetime total punctures by boll weevil females and males within different pupal weight classes. Means followed by the same uppercase letter within each weight class are not significantly different between sexes, and means followed by the same lowercase letter within each sex are not significantly different between weight classes (Tukey-Kramer).

gevity, total developmental time of progeny (egg to adult emergence), percentage of emergence, and percentage of progeny that were female, were examined by one-way analyses of variance using PROC GLM (SAS Institute 1999) to determine the influence of pupal weight. When significant $F$ values were obtained, means were separated using the TukeyKramer test (TUKEY option of the LSMEANS statement, SAS Institute 1999). Percentage data were analyzed as arcsine square-root-transformed proportions (Sokal and Rohlf 1995), but results are presented as untransformed means.

Because we observed differences among pupal weight classes in both lifetime oviposition and female longevity, the relationships between these two parameters were explored by covariance analysis by using PROC MIXED (Littell et al. 1997). The model included lifetime oviposition as the dependent variable, pupal weight class as the independent variable, and longevity as a covariate. Relationships corresponding to the respective pupal weight classes were examined for coincidence of the regression lines, and for common slopes. Differences among the slopes of regressions corresponding to individual weight classes were then assessed through pairwise comparisons using the ESTIMATE statement in PROC MIXED.

The proportion of days on which each female oviposited was calculated by dividing the number of days during which each female laid one or more eggs by the total longevity in days. The proportions of days on which females oviposited were then compared among pupal weight classes using a log likelihood G-test (Zar 1999). The proportions of females laying one or more eggs during their lifetimes were similarly compared among pupal weight classes by using a log-likelihood $G$-test.

Each respective relationship between female pupal weight and total oviposition punctures, total feeding punctures, the ratio of oviposition punctures to total punctures, and the proportion of squares with one or more punctures, was described by a simple linear regression calculated using PROC GLM (SAS Institute 1999). The numbers of oviposition punctures observed for each weevil each day were examined by repeated measures analysis using PROC MIXED (Littell et al. 1997). The model used a compound symmetry covariance structure and contained terms for time (day), pupal weight, and their interaction.

The influence of pupal weight on patterns of subsequent adult survival was examined separately for each weevil sex. Homogeneity of survival curves among pupal weight classes was tested with the logrank $\chi^{2}$ statistic of the LIFETEST procedure of SAS (SAS Institute 1999). Subsequently, a closed testing procedure (Hommel 1988) was used to determine whether survival curves for different weight classes could be distinguished.

An estimate of boll weevil population growth rate was obtained for females corresponding to each pupal weight class by calculating life table statistics. For each treatment, the jackknife program of Hulting et al. (1990) was used to calculate the net reproductive rate $\left(R_{o}\right)$, the intrinsic rate of natural increase $\left(r_{m}\right)$, the finite capacity of increase ( $\lambda$, defined as the number of times a population multiplies itself per unit of time), the mean generation time $(\mathrm{T})$, the doubling time (DT) of the population, and the total progeny produced per female.

\section{Results}

The number of lifetime punctures differed between sexes $(F=17.3 ; \mathrm{df}=1,334 ; P<0.01)$ and among pupal weight classes $(F=21.8 ; \mathrm{df}=4,334 ; P<0.01)$. The average number of total punctures produced by females, including both feeding and oviposition punctures $(302.6 \pm 24.0)$, was 1.6 -fold higher than the total made by males $(190.4 \pm 9.5)$. Lifetime punctures tended to increase with pupal weight (Fig. 1). The interaction between pupal weight class and weevil sex was not significant $(F=0.9 ; \mathrm{df}=4,334 ; P=0.50)$,

Table 1. Regression parameters relating female boll weevil pupal weight (pwt) to daily oviposition punctures (OP), daily feeding punctures (FP), ratio of oviposition punctures to total punctures (OP/[OP+FP]), and total squares attacked (SA)

\begin{tabular}{lccrrr}
\hline \hline \multicolumn{1}{c}{ Relation } & $n$ & Slope $(\mathrm{SE})$ & $P_{\text {slope }}$ & \multicolumn{1}{c}{ Intercept $(\mathrm{SE})$} & $R_{\text {intercept }}$ \\
\hline pwt-OP & 170 & $0.232(0.032)$ & $<0.01$ & $-0.175(0.474)$ & 0.71 \\
pwt-FP & 170 & $0.116(0.041)$ & $<0.01$ & $5.218(0.598)$ & 0.233 \\
pwt-OP/[OP+FP] & 170 & $0.016(0.002)$ & $<0.01$ & $0.033(0.024)$ & 0.046 \\
pwt-SA & 170 & $0.019(0.002)$ & $<0.01$ & $0.345(0.035)$ & $<17$ \\
\hline
\end{tabular}


Table 2. Effects of boll weevil female pupal weight on the emergence and development time of progeny, and on the percentage of female progeny

\begin{tabular}{cccc}
\hline \hline $\begin{array}{c}\text { Pupal } \\
\text { wt(mg) }\end{array}$ & $\begin{array}{c}\text { Completed } \\
\text { development }(\%)\end{array}$ & $\begin{array}{c}\text { Developmental } \\
\text { time }(\mathrm{d})\end{array}$ & $\begin{array}{c}\text { Female } \\
\text { progeny }(\%)\end{array}$ \\
\hline$\leq 5$ & $38.5 \pm 7.4 \mathrm{~b}$ & $16.9 \pm 0.5 \mathrm{a}$ & $28.0 \pm 10.9 \mathrm{~b}$ \\
$6-10$ & $44.2 \pm 5.0 \mathrm{~b}$ & $15.9 \pm 0.5 \mathrm{a}$ & $40.6 \pm 2.8 \mathrm{ab}$ \\
$11-15$ & $73.6 \pm 5.8 \mathrm{a}$ & $16.7 \pm 0.5 \mathrm{a}$ & $58.3 \pm 7.8 \mathrm{a}$ \\
$16-20$ & $72.8 \pm 5.3 \mathrm{a}$ & $15.4 \pm 0.3 \mathrm{a}$ & $62.5 \pm 3.9 \mathrm{a}$ \\
$>20$ & $66.1 \pm 3.3 \mathrm{a}$ & $15.0 \pm 0.4 \mathrm{a}$ & $67.2 \pm 4.1 \mathrm{a}$ \\
\hline
\end{tabular}

Means $\pm \mathrm{SE}$ within a column followed by different letters are significantly different (Tukey-Kramer).

indicating that the effects of pupal weight class on lifetime production of punctures was similar for both sexes.

Average daily oviposition increased with female pupal weight $(F=52.4$; df $=1,170 ; P<0.01$; Table 1$)$. Similarly, increases in female pupal weight were accompanied by increases in the average daily number of feeding punctures $(F=8.0$; df $=1,170 ; P<0.01)$, the ratio of oviposition punctures to total punctures $(F=93.3 ; \mathrm{df}=1,170 ; P<0.01)$, and the average proportion of squares that were attacked each day $(F=59.3 ; \mathrm{df}=1,170 ; P<0.01)$ (Table 1). Overall, $40.2 \pm 3.5 \%$ of the squares provided were punctured by females with pupal weights $\leq 5 \mathrm{mg}$, whereas $50.1 \pm$ $4.0,63.1 \pm 4.0,67.9 \pm 3.4$, and $71.0 \pm 3.6 \%$ of squares were punctured by females in respective weight classes of $6-10,11-15,16-20$, and $>20 \mathrm{mg}$.

The percentage of progeny that developed to adulthood differed among pupal weight classes of the female parents $(F=7.8 ; \mathrm{df}=4,85 ; P<0.01)$. Oviposition by females with pupal weights $>10 \mathrm{mg}$ produced a significantly higher percentage of eggs yielding adult progeny compared with smaller females (Table 2). Female pupal weight class also influenced the proportion of progeny that were female $(F=4.9 ; \mathrm{df}=4$, $85 ; P<0.01)$. Females with pupal weights $>10 \mathrm{mg}$ produced a higher percentage of female progeny than those with pupal weights $\leq 5 \mathrm{mg}$. However, the size of female parents did not significantly influence offspring developmental time $(F=3.1 ; \mathrm{df}=4,45 ; P=$ 0.523; Table 2).

Adult female longevity increased with pupal weight, with females obtained from pupae weighing $>10 \mathrm{mg}$ living significantly longer than those obtained from smaller pupae $(F=11.9$; $\mathrm{df}=4,167 ; P<0.01$; Table

Table 3. Effects of boll weevil female pupal weight on longevity and lifetime oviposition

\begin{tabular}{ccc}
\hline $\begin{array}{c}\text { Pupal } \\
\text { wt(mg) }\end{array}$ & Longevity $(\mathrm{d})$ & $\begin{array}{c}\text { Oviposition } \\
\text { punctures }\end{array}$ \\
\hline$\leq 5$ & $8.2 \pm 1.0 \mathrm{~b}$ & $8.2 \pm 2.9 \mathrm{c}$ \\
$6-10$ & $19.9 \pm 2.8 \mathrm{~b}$ & $54.0 \pm 17.6 \mathrm{~b}$ \\
$11-15$ & $32.6 \pm 3.7 \mathrm{a}$ & $135.4 \pm 21.2 \mathrm{a}$ \\
$16-20$ & $35.4 \pm 3.8 \mathrm{a}$ & $136.0 \pm 20.4 \mathrm{a}$ \\
$>20$ & $43.6 \pm 6.6 \mathrm{a}$ & $132.9 \pm 18.0 \mathrm{a}$ \\
\hline
\end{tabular}

Means \pm SE within a column followed by different letters are significantly different (Tukey-Kramer)
Table 4. Regression equations relating adult longevity to lifetime oviposition for female boll weevils corresponding to different pupal weight classes

\begin{tabular}{cccrrr}
\hline \hline $\begin{array}{c}\text { Pupal } \\
\text { wt(mg) }\end{array}$ & $n$ & Slope (SE) & $P_{\text {slope }}$ & Intercept (SE) & $P_{\text {intercept }}$ \\
\hline$\leq 5$ & 30 & $1.72(2.94) \mathrm{ab}$ & 0.56 & $-6.11(28.98)$ & 0.83 \\
$6-10$ & 36 & $5.08(0.89) \mathrm{a}$ & $<0.01$ & $-47.30(22.95)$ & 0.04 \\
$11-15$ & 40 & $4.06(0.59) \mathrm{a}$ & $<0.01$ & $-0.11(24.01)$ & $>0.99$ \\
$16-20$ & 41 & $2.34(0.56) \mathrm{b}$ & $<0.01$ & $53.44(24.03)$ & 0.03 \\
$>20$ & 25 & $1.56(0.54) \mathrm{b}$ & $<0.01$ & $64.82(29.35)$ & 0.03 \\
\hline
\end{tabular}

Slopes (SE) within a column followed by different letters are significantly different (comparison-wise error rate 0.05 ).

3). Lifetime oviposition also increased with pupal weight class up to the $11-15 \mathrm{mg}$ class $(F=9.3$; $\mathrm{df}=4$, 167; $P<0.01$; Table 3$)$. The total number of lifetime oviposition punctures produced by females with pupal weights $>10 \mathrm{mg}$ were $\approx 16$-fold higher than for females weighing $<5 \mathrm{mg}$.

Analyses of covariance indicated the relationships between lifetime oviposition $(y)$ and longevity $(x)$ were not described by a common, coincident regression for all weight classes $(F=21.25$; $\mathrm{df}=5,162 ; P<$ 0.01 ) and that at least one of the regression slopes differed from those of the other weight classes $(F=$ 4.30; df $=4,162 ; P<0.01)$. Lifetime oviposition was not statistically related to longevity for weevils of the lowest pupal weight class (Table 4). The lack of this relationship likely resulted from the substantial percentage of weevils in this weight class that did not oviposit (45\%) at any time during the study. For weevils associated with pupal weights $>5 \mathrm{mg}$, slopes of the regressions relating oviposition to longevity tended to decrease with increasing pupal weight class (Table 4). Thus, an influence of longevity on lifetime oviposition was observed for all weight classes $>5 \mathrm{mg}$, but this influence was diminished at pupal weights $>15 \mathrm{mg}$.

The percentage of days on which females oviposited during their lifetime increased with higher pupal weight $(G=111.6$, df $=4, P<0.01)$. On average, females weighing $\leq 5 \mathrm{mg}$ oviposited on $37.2 \%$ of days of their lifetime. Females in weight classes of 6-10, $11-15,16-20$, and $>20 \mathrm{mg}$ laid eggs on $43.8,74.6,81.3$, and $93.3 \%$ of days in their lifetimes, respectively. The proportion of females that were gravid (oviposited at least once) also increased with pupal weight $(G=$ 10.6, $\mathrm{df}=2, P<0.01)$. Approximately 54.7, 75.0, and $90.0 \%$ of females in pupal weight classes of $\leq 5,6-10$ and 11-15 mg, respectively, oviposited at least once. All females weighing $\geq 16 \mathrm{mg}$ oviposited at least once.

Oviposition was significantly influenced by both time (days postconditioning) $(F=3.9 ; \mathrm{df}=118,1,903$ $P<0.01)$ and female pupal weight class $(F=18.4 ; \mathrm{df}=$ 4,$107 ; P<0.01$ ) (Fig. 2). In addition, the time by pupal weight class interaction was significant $(F=1.5$; $\mathrm{df}=$ 298, 2,918; $P<0.01$ ), indicating that the temporal pattern of oviposition activity differed among female pupal weight classes. For females with pupal weights $\leq 5 \mathrm{mg}$, oviposition did not begin until day 8 after the conditioning period, after which the average number of oviposition punctures slowly increased to a plateau 

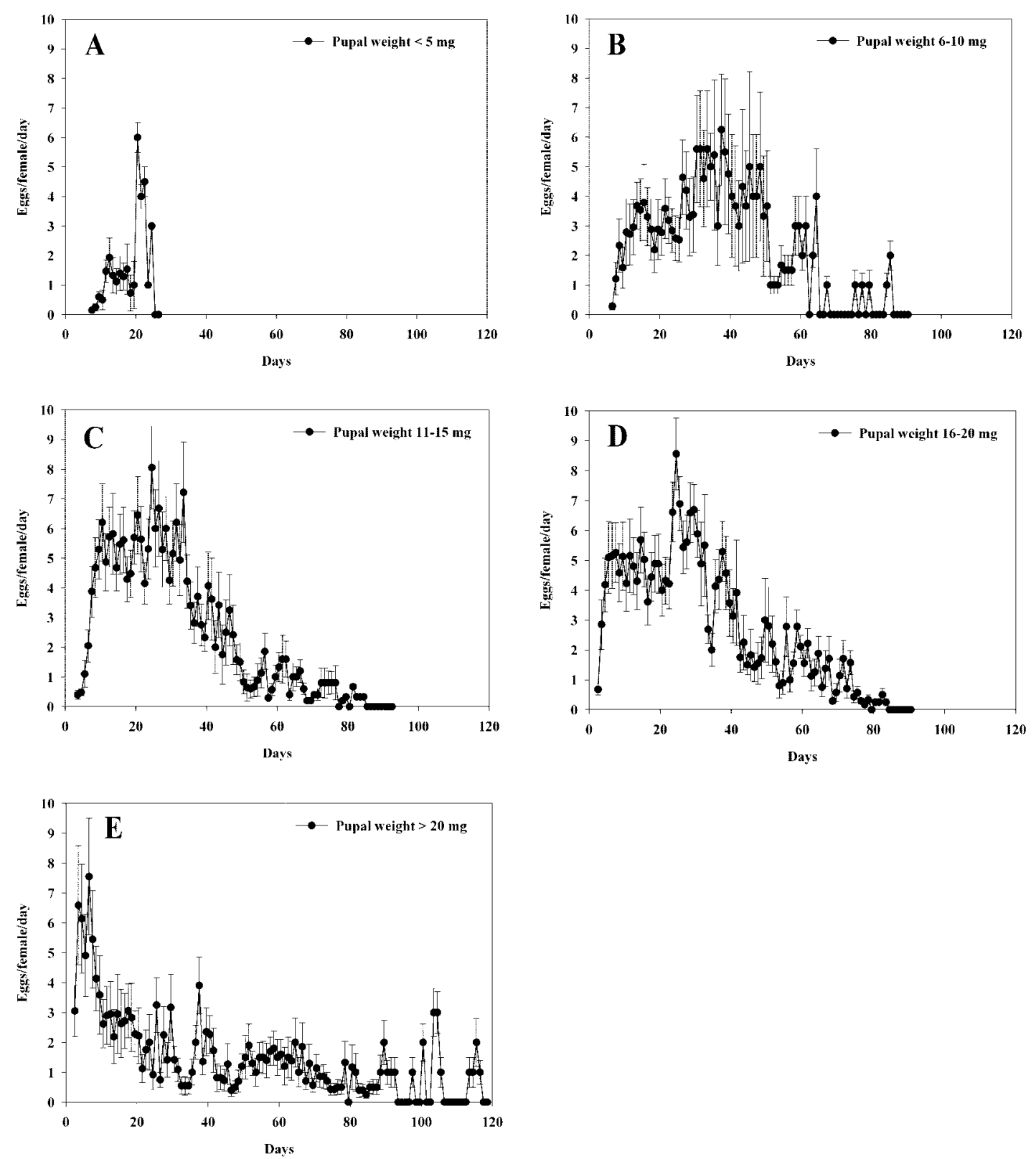

Fig. 2. Lifetime profiles of daily mean $\pm \mathrm{SE}$ oviposition activity of boll weevil females in response to different categories of pupal weight (A) $\leq 5 \mathrm{mg}$, (B) 6-10 mg, (C) 11-15 mg, (D) 16-20 mg, and (E) $>20 \mathrm{mg}$.

of $\approx 1$ egg per day for $\approx 10 \mathrm{~d}$, with a short $(3 \mathrm{~d})$ peak at $\approx 5$ eggs per day, followed by a rapid decline in oviposition (Fig. 2A). No females in this pupal weight class laid eggs beyond day 25. A similar pattern of oviposition was observed for females in the pupal weight class from 6 to $10 \mathrm{mg}$, except the duration of each of the phases of the pattern (plateau, peak, and decline) were greatly lengthened, and the oviposition rates were higher, compared with the smaller females (Fig. 2B). The last egg laid by a female in the 6-10-mg class was oviposited on day 85 . For females in weight classes of 11-15 and 16-20 mg, oviposition began earlier (days 2 and 3 after the conditioning period, respectively), the plateau preceding peak oviposition was less distinct, and oviposition rates were generally higher than for the smaller weevils (Fig. 2C and D). However, in both classes the period of peak oviposition was $\approx 20 \mathrm{~d}$, followed by a gradual decline in oviposition until beyond day 80 . The peak in oviposition for the heaviest weevils (pupal weights $>20 \mathrm{mg}$ ) occurred earlier and for a shorter duration than for smaller weevils, but these heavier females continued 


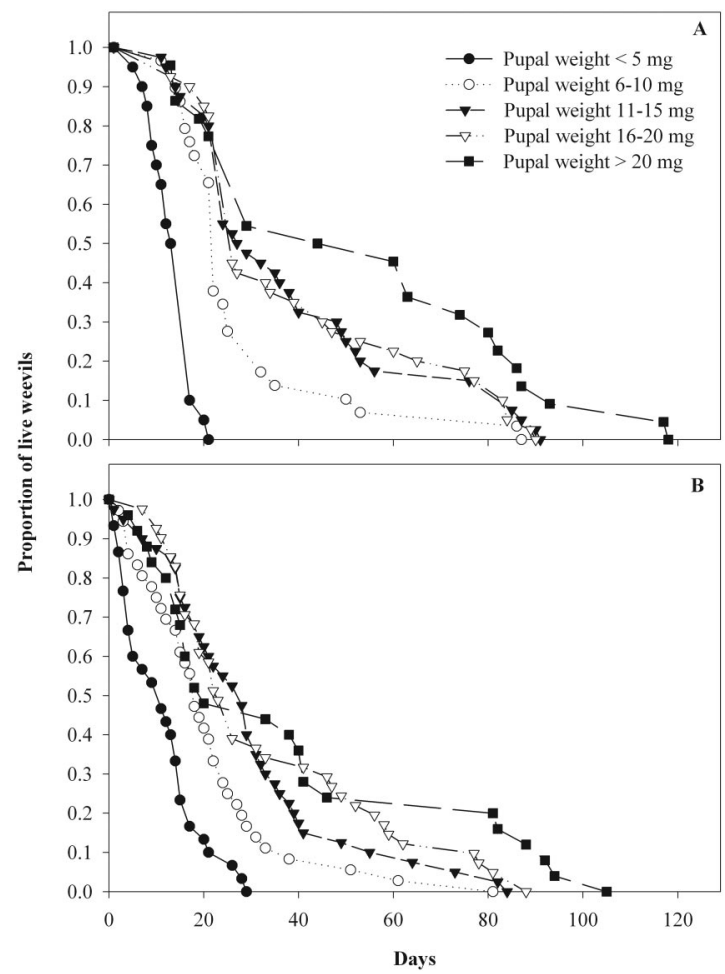

Fig. 3. Survivorship (percentage of live weevils) profiles of boll weevil (A) females and (B) males in relation to different categories of pupal weight.

to produce approximately one to three eggs per day for nearly $120 \mathrm{~d}$ (Fig. 2E).

Weevil survivorship (percentage of weevils remaining alive each day) varied significantly among pupal weight classes for both females $\left(\chi^{2}=107.2, \mathrm{df}=4, P<\right.$ $0.01)$ and males $\left(\chi^{2}=53.9\right.$, df $\left.=4, P<0.01\right)$. The pairwise comparisons revealed that survivorship of females with pupal weights $\leq 5 \mathrm{mg}$ was the lowest of the five weight categories $\left(\chi^{2} \geq 24.7\right.$, df $=1, P<0.01$, Fig. 3A). Survivorships of females with pupal weights $\leq 10 \mathrm{mg}$ were significantly lower than those of females with pupal weights $>10 \mathrm{mg}\left(\chi^{2} \geq 8.2, \mathrm{df}=1, P<0.01\right)$. However, individuals within weight categories 11-15, $16-20$, and $>20 \mathrm{mg}$ had comparable survivorships $\left(\chi^{2}\right.$ $\leq 2.5$, df $=1, P>0.11$ ). Comparisons of male survivorship indicated trends similar to those for females. Survivorship of males with pupal weights $\leq 5 \mathrm{mg}$ was lower than for other pupal weight classes $\left(\chi^{2} \geq 10.8\right.$, df $=1, P<0.01$, Fig. 3B). Survivorship of males within the 6-10-mg pupal weight class was similar to that for males in the 11-15-mg class but was less than for weevils in heavier weight classes $\left(\chi^{2} \geq 6.4, \mathrm{df}=1, P \leq\right.$ $0.01)$. Survivorship of males associated with pupal weights $>10 \mathrm{mg}$ was similar among weight classes $\left(\chi^{2}\right.$ $\leq 2.4$, df $=1, P \geq 0.11$ ).

The values of life table statistics calculated for boll weevil females differed among pupal weight categories (Table 5). Populations of boll weevils with pupal weights $>10 \mathrm{mg}$ are predicted to grow at significantly higher mean constant exponential rates $\left(r_{m}\right)$ than those with pupal weights $\leq 10 \mathrm{mg}$. Life table calculations indicated that boll weevil populations with pupal weights of $>10 \mathrm{mg}$ will increase an average 8.4-fold each generation $\left(R_{o}\right)$ higher than for females with weights $\leq 5 \mathrm{mg}$ or $6-10 \mathrm{mg}$. The DT of weevils with pupal weights $\leq 5 \mathrm{mg}$ could not be estimated because the population was not increasing $\left(r_{m}\right.$ was not different from zero).

\section{Discussion}

Positive relationships between adult or pupal weight or size and resulting egg complement or fecundity have been reported in several Lepidoptera (Bragg 1970, Miller et al. 1982, Wagner et al. 1987, Spurgeon et al. 1995, Greenberg et al. 2001), Diptera (Hawley 1985, Krainacker et al. 1989), and Hymenoptera (Zhang and Wagner 1991, Eliason and McCullough 1997). Many authors have reported that among arthropod predators and parasitoids there is often a positive correlation between body size or weight and reproductive potential (O'Neill and Skinner 1990, Croft and Copland 1993, Zheng et al. 1993, Greenberg et al. 1995). Comparatively few studies have explored this relationship within the Coleoptera. Pupal weight was not a good indicator of fecundity or adult longevity for the cottonwood leaf beetle, Chrysomela scripta F. (Coyle et al. 1999), but larval development rate and survival of progeny to adulthood in the coccinellids Adelia bipunctata (L.) and Coccinella transversalis $\mathrm{F}$. were influenced by the weights of the parents (Francis et al. 2001, Omkar and James 2004).

In our study on the boll weevil, we found no negative impact of small parent size on developmental rate, but small size of the female parent was associated with reduced survival and emergence of adult progeny, and with reductions in the proportions of progeny that were female. Our analyses detected relationships

Table 5. Life table statistics of boll weevil females as affected by the pupal weights (values in parentheses are 95\% confidence intervals)

\begin{tabular}{cccccc}
\hline \hline Pupal wt $(\mathrm{mg})$ & $\mathrm{R}_{\mathrm{o}}$ & \multicolumn{1}{c}{$\mathrm{r}_{\mathrm{m}}$} & \multicolumn{1}{c}{$\lambda$} & $\mathrm{T}$ & $\mathrm{DT}$ \\
\hline$\leq 5$ & $1.3(0.4-2.2)$ & $0.023(-0.03-0.09)$ & $1.02(0.97-1.09)$ & $12.5(-2.61-16.98)$ & \\
$6-10$ & $12.0(4.2-19.8)$ & $0.132(0.10-0.17)$ & $1.14(1.10-1.18)$ & $18.8(14.69-23.46)$ & $5.2(3.6-6.7)$ \\
$11-15$ & $57.7(38.5-77.0)$ & $0.218(0.19-0.25)$ & $1.24(1.21-1.28)$ & $18.6(16.20-21.12)$ & $3.2(2.8-3.6)$ \\
$16-20$ & $63.2(44.2-82.1)$ & $0.231(0.19-0.27)$ & $1.26(1.21-1.31)$ & $18.0(14.91-21.08)$ & $3.0(2.5-3.5)$ \\
$>20$ & $47.0(34.8-59.1)$ & $0.201(0.13-0.26)$ & $1.22(1.13-1.30)$ & $19.2(13.07-25.16)$ & $3.3(3.4-4.6)$ \\
\hline
\end{tabular}

$\mathrm{R}_{\mathrm{o}}$, net reproductive rate; $\mathrm{r}_{\mathrm{m}}$, intrinsic rate of increase; $\lambda$, finite rate of increase; $\mathrm{T}$, mean period over which progeny are produced (days); DT, doubling time of the population (days). 
between female pupal weight and mean numbers of feeding punctures per day, oviposition punctures per day, the proportion of oviposition punctures to total punctures, and the proportion of squares attacked. However, fit of these relationships indicated by respective $R^{2}$ values were relatively poor. These poor fits may suggest that other, unidentified factors influenced these responses during the experiment. More likely, this variation in response was indicative of the variation among weevils obtained from similarly sized pupae.

More importantly, our results demonstrate severe penalties for the smallest adults in terms of longevity, oviposition rates, survival of progeny, proportion of progeny that are female, and duration of the oviposition period. Because many of these effects are multiplicative, their joint impacts on population growth can be substantial. For example, the number of female progeny produced per a fixed number of eggs was $\approx 4$.1-fold higher for weevils in the highest pupal weight class $(>20 \mathrm{mg}$ ) compared with weevils in the lowest weight class $(\leq 5 \mathrm{mg})$ because weevils in the latter group suffered reduced survival of progeny and a reduced proportion of progeny that were female. When these penalties are combined with an $\approx 16$-fold difference in oviposition between the two extreme weight classes, the total difference in the lifetime production of female progeny by weevils of the two weight classes is $\approx 64$-fold.

Although the boll weevil commonly exhibits wide variation in adult size, our study is the first to examine the reproductive consequences of small parent size. These consequences are sufficiently severe to have substantial population impacts for the smallest adult weevils. Although small size negatively affected female reproductive potential, it did not preclude reproduction even for weevils in the lowest weight class. However, the penalties imposed on the smallest weevils were so severe that life table analyses could not detect a population increase for this group.

Considerable effort has been devoted to investigating cultural means of maximizing mortality of developing boll weevil larvae. None of these efforts recognized the potential benefits of reduced adult size of surviving weevils. However, they have resulted in the availability of numerous cultural methods to make the environment of the developing boll weevil larva less hospitable. Included in these methods are manipulation of planting bed shape, row width, and row direction (Slosser 1981, Slosser et al. 1986), delayed planting (Fuchs et al. 1998, Walker and Smith 1996), the use of okra-leaf varieties (Jenkins and Wilson 1996), and careful management of nitrogen fertility (Niles et al. 1978). In addition, use of alternative irrigation strategies, such furrow irrigation in alternate rows, may minimize the favorable influences of irrigation on the development and survival of immature weevils. Our results strongly suggest the potential for impacting boll weevil populations through these and other cultural practices beyond the previous emphasis on maximizing natural mortality.

\section{Acknowledgments}

We acknowledge the technical assistance of J. Alejandro, J. Caballero, R. Domingues, and L. Leal. We are grateful to Drs. E. Villavaso (USDA-ARS, Biological Control and Mass Rearing Research Unit, Mississippi State, MS) and K. R. Summy (Department of Biology, University of Texas Pan American, Edinburg, TX) for critical reviews of the manuscript.

\section{References Cited}

Bailey, J. C., F. G. Maxwell, and J. N. Jenkins. 1967. Boll weevil antibiosis with selected cotton lines utilizing eggimplantation techniques. J. Econ. Entomol. 60: 1275-1279.

Black, J. H., and T. F. Leigh. 1963. The biology of the boll weevil in relation to cotton type. J. Econ. Entomol. 56: 789-790.

Bragg, D. E. 1970. Insemination and fecundity in the artichoke plume moth, Platyptilia carduidactyla (Lepidoptera: Pterophoridae). Ann. Entomol. Soc. Am. 63: 334335.

Coyle, D. R., J. D. McMillin, and E. R. Hart. 1999. Pupal and adult parameters as potential indicators of cottonwood leaf beetle (Coleoptera: Chrysomelidae) fecundity and longevity. J. Econ. Entomol. 93: 713-720.

Croft, P., and Copland, M. 1993. Size and fecundity in Dasnusa sibirica Telenga. Bull. OILB/SROP 16: 53-56.

Curry, G. L., J. R. Cate, and P.J.H. Sharpe. 1982. Cotton bud drying: contributions of boll weevil mortality. Environ. Entomol. 11: 344-350.

Eliason, E. A., and D. G. McCullough. 1997. Survival and fecundity of three insects reared on four varieties of scotch pine Christmas trees. J. Econ. Entomol. 90: 15981608.

Everett, T. R., and J. O. Ray. 1962. The utility of sealed punctures for studying fecundity and egg laying by the boll weevil. J. Econ. Entomol. 55: 634-637.

Francis, F., E. Haubruge, P. Hastir, and C. Gaspar. 2001. Effect of aphid host plant on development and reproduction of the third trophic level, the predator Adalia bipunctata (Coleoptera: Coccinellidae). Environ. Entomol. 30: 947-952.

Fuchs, T. W., D. R. Rummel, and E. P. Boring, III. 1998. Delayed uniform planting for areawide boll weevil suppression. Southwest. Entomol. 23: 325-333.

Greenberg, S. M., T. W. Sappington, B. C. Legaspi, Jr., T.-X. Liu, and M. Sétamou. 2001. Feeding and life history of Spodoptera exigua (Lepidoptera: Noctuidae) on different host plants. Ann. Entomol. Soc. Am. 94: 566-575.

Greenberg, S. M., J. A. Morales-Ramos, E. G. King, K. R. Summy, and M. G. Rojas. 1995. Biological parameters for mass propagation of Catolaccus grandis (Hymenoptera: Pteromalidae). Environ. Entomol. 24: 1322-1327.

Hawley, W. A. 1985. A high-fecundity aedine: factors effecting egg production of the western treehole mosquito, Aedes sierrensis (Diptera: Culicidae). J. Med. Entomol. 22: 220-225.

Hommel, G. 1988. A stage wise rejective multiple test procedure based on a modified Bonferroni test. Biometrica 75: 383-386.

Hulting, F. L., B. Orr, and J. J. Obrycki. 1990. A computer program for calculation and statistical comparison of intrinsic rates of increase and associated life table parameters. Fla. Entomol. 73: 601-612.

Jenkins, J. N., and F. D. Wilson. 1996. Host plant resistance, pp. 563-597. In E. G. King, J. R. Phillips, and R. J. Coleman [eds.]. Cotton insects and mites: characterization and 
management. Cotton Foundation Reference Book Series, No. 3. The Cotton Foundation Publisher, Memphis, TN.

Krainacker, D. A., J. R. Carey, and R. I. Vargas. 1989. Sizespecific survival and fecundity for laboratory strains of two tephritid (Diptera: Tephritidae) species: implications for mass rearing. J. Econ. Entomol. 82: 104-108.

Littell R. C., G. A. Milliken, W. W. Stoup, and R. D. Wolfinger. 1997. SAS system for mixed models. SAS Institute, Cary, NC.

Little, V. A., and D. F. Martin. 1942. Boll weevils, pp. 1-21. In Cotton insects of the United States. Burgess Publishing Co., Minneapolis. MN.

Mally, F. W. 1901. The Mexican boll weevil. U.S. Dep. Agric. Farmers' Bull. 130.

Miller, T. A., W. J. Cooper, and J. W. Highfill. 1982. Relationships between pupal size and egg production in reared female Antheraea polyphemus. Ann. Entomol. Soc. Am. 75: 107-108.

Newell, W., E. F. Grossman, and A. F. Camp. 1926. The Mexican cotton boll weevil, pp. 223-247. Fla. Agric. Exp. St. Bull. 180

Niles, G. A., L. H. Harvey, and J. K. Walker. 1978. Cultural control of the boll weevil, pp. 23-38. In Boll weevil: management strategies. Southern Coop. Serv. Bull. 228.

Omkar, C., and B. E. James. 2004. Influence of prey species on immature survival, development, predation and reproduction of Coccinella transversalis Fabricius (Col. Coccinelidae). J. Appl. Entomol. 128: 150-159.

O’Neill, K. M., and S. W. Skinner. 1990. Ovarian egg size and number in relation to female size in five species of parasitoid wasps. J. Zool. 220: 115-122.

Reardon, B. J., and D. W. Spurgeon. 2002. Critical weights of boll weevil (Coleoptera: Curculionidae) larvae in relation to square desiccation and natural mortality. Environ. Entomol. 31: 972-976.

Sappington, T. W., and D. W. Spurgeon. 2000. Preferred technique for adult sex determination of the boll weevil (Coleoptera: Curculionidae). Ann. Entomol. Soc. Am. 93: $610-615$.

SAS Institute. 1999. SAS/STAT user's guide, release 8.01 ed. SAS Institute, Cary, NC.

Slosser, J. F. 1981. Cultural control of the boll weevil: influence of bed shape. J. Econ. Entomol. 74: 561-565.

Slosser, J. F., G. J. Puterka, and J. R. Price. 1986. Cultural control of the boll weevil (Coleoptera: Curculionidae) effects of narrow-row spacing and row direction. J. Econ. Entomol. 79: 378-383.

Smith, G. D. 1921. Studies in the biology of the Mexican cotton boll weevil on short-staple upland, long-stapled upland, and Sea Island cottons. U.S. Dep. Agric. Bull. 926.

Smith, G. L. 1936. Percentage and causes of mortality of boll weevil stages within the squares. J. Econ. Entomol. 29: 99-105.

Sokal, R. R., and F. J. Rohlf. 1995. Biometry. The principles and practice of statistics in biological research, 3rd ed. W. H. Freeman and Co., New York

Spurgeon, D. W., P. D. Lingren, T. N. Shaver, and J. R Raulston. 1995. Realized and potential fecundity of the Mexican rice borer (Lepidoptera: Pyralidae) as a function of pupal weight. Environ. Entomol. 24: 94-98.

Sturm, M. M., and W. L. Sterling. 1986. Boll weevil mortality factors within flower buds of cotton. Bull. Entomol. Soc. Am. 32: 239-247.

Sturm, M. M., and W. L. Sterling. 1990. Geographical patterns of boll weevil mortality: observations and hypothesis. Environ. Entomol. 19: 59-65.

Sturm, M. M., W. L. Sterling, and Hartstack. 1990. Role of natural mortality in boll weevil (Coleoptera: Curculionidae) management programs. J. Econ. Entomol. 83: 1-7.

Wagner, M. R., K. M. Clancy, and D. M. Kirkbride. 1987. Predicting number of oocytes in adult spruce budworm, Choristoneura occidentalis (Lepidoptera: Tortricidae). Environ. Entomol. 16: 551-555.

Walker, J. K., and C. W. Smith. 1996. Cultural control, pp. 471-509. In E. G. King, J. R. Phillips, and R. J. Coleman [eds.], Cotton insects and mites: characterization and management. Cotton Foundation Reference Book Series, No. 3. The Cotton Foundation Publisher, Memphis, TN.

Zar, J. H. 1999. Biostatistical analysis, 4th ed. Prentice Hall Upper Saddle River, NJ.

Zhang, Z. Y., and M. R. Wagner. 1991. Cocoon and adult parameters predict fecundity of the pine sawfly Neodipirion fulviceps. Southwest. Entomol. 16: 193-198.

Zheng, Y., K. S. Hagen, K. M. Daane, and T. E. Mittler. 1993. Influence of larval food consumption on the fecundity of the lacewings Chrysoperla carnea. Entomol. Exp. Appl. 67: $9-14$.

Received 27 August 2004; accepted 30 January 2005. 